\title{
DEVELOPMENT OF A FUNGAL INOCULUM FOR EFFICIENT PHOSPHATE UTILIZATION IN AGRICULTURE
}

\author{
P. D. S. U. Kumari, C. M. Nanayakkara and J. M. A. U. Bandara \\ Department of Plant Sciences, University of Colombo, Sri Lanka \\ Email_samanthiu@gmail.com_Tel - ++94112585038
}

\begin{abstract}
With the aim of developing an environment friendly P biofertilizer, phosphate solubilizing fungi (PSF) were isolated from Sri Lankan soil. A total of 12 fungal isolates, showing phosphate solubilizing activities were isolated from bulk and rhizosphere soils of different agro-ecological zones. The best 11 P solubilizers selected by three levels of screening were further evaluated for their efficiency in phosphate solubilization in Pikovskaya liquid media containing tricalcium phosphate and High Grade Eppawala Rock Phosphate (HERP) using two parameters: solubilized P concentration and media $\mathrm{pH}$ due to organic acid production. In contrast to all isolates being able to mediate high amount of $\mathrm{P}$ solubilization in PVK medium, they were less efficient in solubilizing HERP in modified PVK medium. Among the $11 \mathrm{PSF}$, fungal isolate KBF4 accounted for the highest $\mathrm{Ca}_{3}\left(\mathrm{PO}_{4}\right)_{2}$ solubilization while KBF2 accounted for the highest HERP solubilization. Acidification of the culture media seemed to be the main mechanism of $\mathrm{P}$ solubilization in both media indicating a significant $\mathrm{pH}$ decrease of the culture supernatants. A significant correlation between the quantity of $\mathrm{P}$ solubilized and the $\mathrm{pH}$ decrease in PVK liquid media containing $\mathrm{Ca}_{3}\left(\mathrm{PO}_{4}\right)_{2}$ was observed. This relationship was not significant in HERP medium indicating other possible mechanism of phosphate solubilization.
\end{abstract}

Keywords: Phosphate Solubilizing Fungi, phosphate solubilization, Rock Phosphates, biofertilizer

\section{INTRODUCTION}

Phosphorous $(\mathrm{P})$ is an essential macronutrient required for the plant growth and development and next to Nitrogen, generally acts as a restricting factor of plant growth in most soils (Son et al., 2003). Soil contains substantial reserves of total P. However most soil P remains insoluble and only less than $10 \%$ is available for plants (Son et al., 2003). Hence, large quantities of soluble phosphate fertilizers are applied in large amounts to achieve the desired plant productivity. $\mathrm{P}$ deficiency in soils is widespread and $\mathrm{P}$ fertilizers are almost universally required to maintain crop production. Although $\mathrm{P}$ in those fertilizers is initially plant available, it rapidly reacts with the cations and anions in 
The ability of soil microorganisms to convert insoluble forms of $\mathrm{P}$ into an accessible form is an important trait for increasing plant yield. This ability is considered to be one of the most important traits associated with plant $\mathrm{P}$ nutrition. Therefore, phosphate solubilizing microorganisms (PSM) have attracted the attention of agriculturists as soil inoculants to improve the plant growth and development (Chen et al., 2006). Low solubility of the RP and the high cost of conversion of RP in to chemical fertilizer can be overcome by the combined application of the RP with PSM.

Phosphate solubilizing microorganisms (PSM) refer to a group of soil microorganisms that are a component of $\mathrm{P}$ cycle, capable of dissolving insoluble forms of phosphates into plant available forms. Several groups of microorganisms including fungi, bacteria and actinomycetes are known as efficient fixed P solubilizers (Sundara et al., 2002). Among the microorganisms, it is observed that several fungal strains have a higher solubilizing ability of inorganic insoluble phosphates than bacteria (Rajankar et al., 2007). This conversion of insoluble phosphates into soluble forms by microorganisms involves processes of acidulation, ion chelation and exchange reactions (Hameeda et al., 2006). An increase in $\mathrm{P}$ availability to plants through inoculation of PSM not only compensates for high cost of manipulation of fertilizers in industry, but also mobilizes the fertilizer added to the soil by preventing the environmental problems arise by the frequent applications of chemical P fertilizers.

The main objective of this study was to isolate efficient phosphate solubilizing fungi from Sri Lankan soils with the aim of producing a low cost and environmentally friendly biofertilizer.

\section{MATERIALS AND METHODOLOGY}

\section{STUDY SITES AND SOILS}

Soil samples were collected from different sites in Sri Lanka to represent different soil types and agro-ecological zones. Phosphate solubilizing fungi were isolated from the bulk soil and the rhizosphere soil. Bulk soil samples were collected from first $02-05 \mathrm{~cm}$ of depth of land and for the collection of rhizosphere soil, plants were uprooted and the adhering soil was suspended in $5 \mathrm{ml}$ of sterile $1 \%$ saline solution by vigorous shaking of the roots.

\section{ISOLATION AND SCREENING OF PHOSPHATE SOLUBILIZING FUNGI}

Ten fold serial dilutions were prepared using $1 \%$ sterile saline solution as the diluent and were individually inoculated by spreading on a medium described by Pikovskaya in 1948 and modified by Sundara Rao and Sinha in 1986. The medium consists of glucose $10.0 \mathrm{~g}$, $\mathrm{Ca}_{3}\left(\mathrm{PO}_{4}\right)_{2} 5.0 \mathrm{~g}$ as the insoluble $\mathrm{P}$ source, $\left(\mathrm{NH}_{4}\right)_{2} \mathrm{SO}_{4} 0.5 \mathrm{~g}, \mathrm{KCl} 0.2 \mathrm{~g}, \mathrm{MgSO}_{4} .7 \mathrm{H}_{2} \mathrm{O} 0.1 \mathrm{~g}$, $\mathrm{MnSO}_{4} \cdot \mathrm{H}_{2} \mathrm{O} 0.002 \mathrm{~g}, \mathrm{FeSO}_{4} 0.002 \mathrm{~g}$, yeast extract $0.5 \mathrm{~g}$ and agar $15.0 \mathrm{~g}$ per litre. Fungi capable of producing a halo/ clear zone due to solubilization were selected as potential phosphate solubilizers and were further purified into pure cultures by subculturing several times on the same medium. A secondary screening was conducted to ascertain the expression of trait under the presence of partially soluble phosphates in the medium by replacing $\mathrm{Ca}_{3}\left(\mathrm{PO}_{4}\right)_{2} 5.0 \mathrm{~g}$ with $\mathrm{K}_{2} \mathrm{HPO}_{4}$ as described by the Bergerson (1961). The fungal isolates capable of producing a clear halo on this medium were selected for the tertiary screening which was done on a medium containing High Grade Eppawala Rock Phosphate (HERP) as the $\mathrm{P}$ source. Fungi which produced a clear halo in this medium were selected as the candidates for the subsequent experimentation on quantification of phosphate solubilizing ability.

\section{EVALUATION OF THE EFFICIENCY OF PHOSPHATE SOLUBILIZATION}

The selected fungal isolates were tested in two different liquid media containing two different P sources: PVK liquid medium and HERP containing modified PVK liquid medium. The

Proceedings of the 15 ${ }^{\text {th }}$ International Forestry and Environment Symposium, 26-27 November 2010.

Published by Department of Forestry and Environmental Science, University of Sri Jayewardenepura, Sri Lanka. 
efficiency was evaluated using two parameters: quantity of $\mathrm{P}$ solubilized at a given time and the amount of organic acid produced as denoted by a $\mathrm{pH}$ decrease in the medium.

\section{INOCULUM PREPARATION}

Sporulated pure fungal cultures prepared on PVK medium were selected for the preparation of spore suspensions from each fungal isolate. A total volume of $20 \mathrm{ml}$ sterile water was spread in aliquots on a culture plate and the fungal colony surface was lightly scraped using a sterile spreader. The cultures were filtered through Whatman No. 42 filter paper in to a sterile glass bottle. Spore counts were taken using a haemocytometer and the suspension was adjusted to have approximately $1 \times 10^{7}$ spores per $1 \mathrm{ml}$.

\section{PHOSPHATE SOLUBILIZATION ON PVK LIQUID MEDIUM}

A volume of $100 \mathrm{ml}$ PVK liquid media was inoculated with $1 \mathrm{ml}$ of spore suspension of a particular fungal strain containing approximately $1 \times 10^{7}$ spores per $1 \mathrm{ml}$. One millilitre of sterile distilled water inoculated sample was treated as the control and three replicates were maintained for each test fungus. All the samples were kept in a shaker for 24 hours at $100 \mathrm{rpm}$ constant oscillation at room temperature. After incubation, media were filtered through Whatman No. 42 filter paper and centrifuged at $7200 \mathrm{rpm}$ for 20 minutes to remove any suspended solids and mycelial fragments. Supernatants were collected and $10 \mathrm{ml}$ from each were taken for the measurement of $\mathrm{pH}$ values. Remaining suspension was used to measure solubilized P concentrations. Suitable dilutions were done to the original supernatants where necessary and P concentrations were measured using Murphy and Riley method (1963).

\section{PHOSPHATE SOLUBILIZATION ON HERP CONTAINING MODIFIED PVK LIQUID MEDIUM}

For the comparative study of the ability of HERP dissolution, a second medium was prepared replacing $5 \mathrm{~g}$ of $\mathrm{Ca}_{3}\left(\mathrm{PO}_{4}\right)_{2}$ in PVK medium by $7.5 \mathrm{~g}$ of High Grade Eppawala Rock Phosphate and $\mathrm{pH}$ of the medium was adjusted to 7.0 and autoclaved. The procedure, mentioned in the above was repeated with each of 11 test fungal isolates. All the samples were tested for $\mathrm{P}$ solubilization and $\mathrm{pH}$ measurements after 24 and 48 hours of incubation in the shaker under $100 \mathrm{rpm}$ oscillation.

\section{MEASUREMENT OF ORGANIC ACID PRODUCTION}

The most common mechanism used by microorganisms for solubilization of insoluble phosphate is the acidification of the medium by releasing different organic acids. Therefore, to ascertain the mechanism of solubilization and its correlation to $\mathrm{P}$ solubilization, the $\mathrm{pH}$ decrease in the medium was measured at the end of the incubation period. Initial $\mathrm{pH}$ value of the medium was adjusted to 7.0. A volume of $10 \mathrm{ml}$ aliquots of the centrifuged supernatants of all the replicates were taken to measure the final $\mathrm{pH}$ value at room temperature.

\section{STATISTICAL ANALYSIS}

The experiment data were subjected to one-way and two-way ANOVA tests, correlation analysis and multiple mean comparison tests using SPSS 10.0 statistical software package.

\section{RESULTS AND DISCUSSION}

\section{ISOLATION AND SCREENING OF PSF FROM SOIL SAMPLES}

Isolated fungal strains were assigned code number for convenience. The first letter code was given for the locality, a second to denote the bulk (B) or rhizosphere (R) soils and a third letter $(\mathrm{F})$ indicating a fungus. The number was assigned to indicate the successive number of fungi isolated from that sample of soil. Microorganisms capable of producing a clear zone due to $\mathrm{P}$ solubilization in the surrounding medium (Singal et al., 1991) were selected as potential 
phosphate solubilizers and a total of 12 fungal isolates having code numbers KBF1, KBF2, KBF3, KBF4, KBF5, KRF1, RBF1, RBF2, RBF3, RRF1, WBF1 and UBF1were resulted from the primary screening.

It has been reported that some phosphate solubilizing microorganisms suppress their trait of $\mathrm{P}$ solubilization in the presence of partially soluble P (Mikanova et al., 2002). Agricultural soils cannot expect to be devoid of soluble or partially soluble $\mathrm{P}$ as the $\mathrm{P}$ fertilization is routinely done over the years and hence accumulate substantial amounts of phosphates. Therefore, when applied as a biofertilizer, trait suppression would be very undesirable. Hence regulation of phosphate solubilization activity in the presence of partially soluble $\mathrm{P}$ source in medium was determined by the secondary screening. Fungal isolate RRF1 has not shown the production of clear halo in this screening indicating the trait suppression. Other eleven fungal strains were selected for the next level of screening.

Tertiary screening was employed to investigate the ability of PSF to solubilize natural rock phosphates with the aim of using HERP together with PSF as a biofertilizer. HERP is not pure apatite and contains other metal complexes. Some microorganisms are unable to dissolve hardly soluble natural rock phosphates due to these complexes. All the fungal isolates subjected to tertiary screening were able to solubilize HERP in the medium and were further used in the quantification studies of P solubilization.

\section{PHOSPHATE SOLUBILIZATION IN MODIFIED PVK LIQUID MEDIUM}

The amount of phosphates solubilized by different fungal isolates showed significant variability at $5 \%$ significance level $(\mathrm{p}=0.000)$. All fungal isolates significantly increased the soluble P content in comparison with the control, showing effective conversion of inorganic insoluble $\mathrm{P}$ into soluble forms. Table 1 summarizes the mean values of $\mathrm{P}$ solubilized in modified PVK liquid media and the corresponding $\mathrm{pH}$ after 24 hours of incubation. The highest significant solubilization ability of $881.17( \pm 35.43) \mathrm{mg} P / 1$ was observed with the isolate KBF4. The lowest P solubilization of $222.15( \pm 3.14) \mathrm{mg} \mathrm{P} / \mathrm{l}$ was recorded with KBF5. In addition, a significant reduction $(\mathrm{p}=0.000)$ in final $\mathrm{pH}$ of the medium was recorded with the isolate RBF1 showing the lowest recorded $\mathrm{pH}$ of $3.78( \pm 0.087)$. This is a clear indication of acidulation of the medium by PSF in order to solubilize $\mathrm{P}$. The amount of $\mathrm{P}$ solubilized and the $\mathrm{pH}$ decrease of the respective media showed a significant correlation $(\mathrm{p}=0.003)$ of 0.808 shown in figure 1 in PVK liquid medium. Therefore, a clear conclusion can be drawn on the use of $\mathrm{pH}$ as an indicator of $\mathrm{P}$ solubilisation. Also a nonsignificant decrease in $\mathrm{pH}$ was observed in the control most probably due to the dissolution of $\mathrm{CO}_{2}$ in water during constant mixing with air.

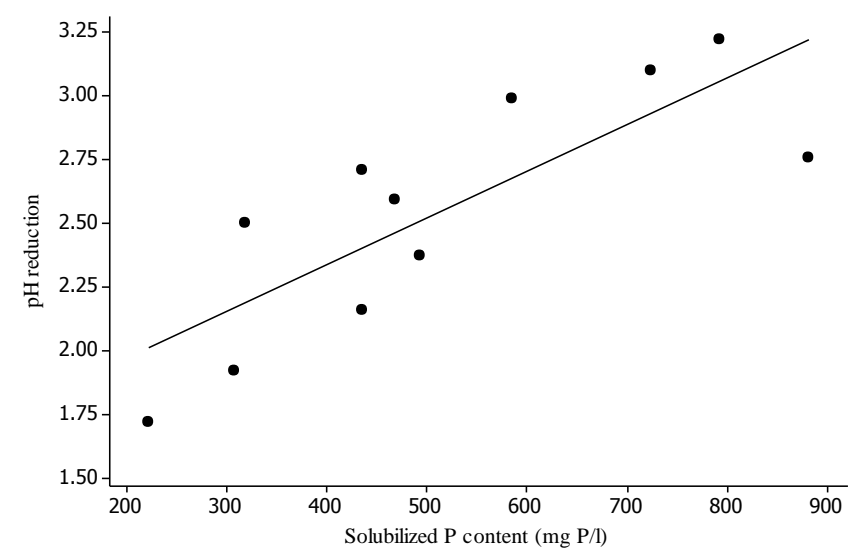

Figure1: Relationship between $\mathrm{pH}$ reduction and solubilized $\mathrm{P}$ content in PVK liquid medium

Proceedings of the 15 ${ }^{\text {th }}$ International Forestry and Environment Symposium, 26-27 November 2010

Published by Department of Forestry and Environmental Science, University of Sri Jayewardenepura, Sri Lanka. 


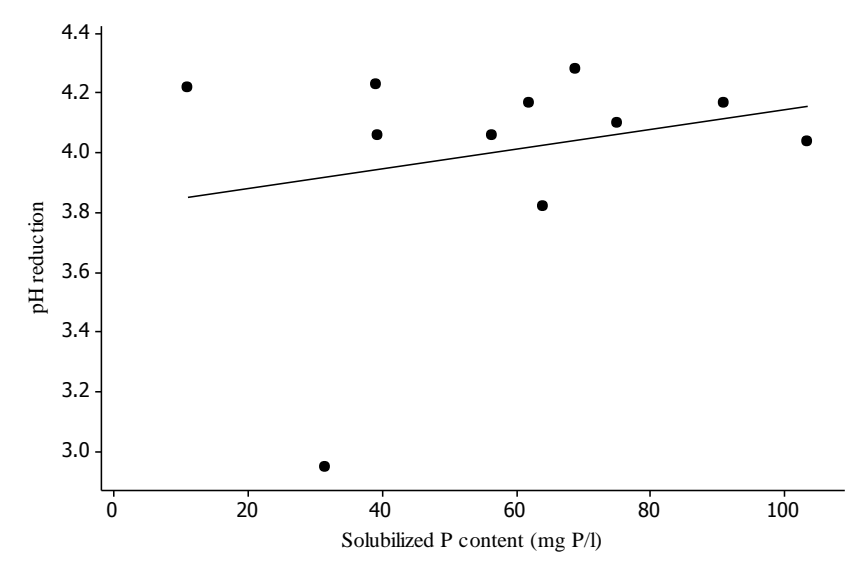

Figure 2: Relationship between $\mathrm{pH}$ reduction and solubilized $\mathrm{P}$ content in PVK liquid medium containing HERP

Table 1: Mean solubilized $\mathrm{P}$ concentrations ( $\mathrm{mg} \mathrm{P} / \mathrm{l})$ and mean $\mathrm{pH}$ after 24 hour incubation in PVK medium: The standard error of the mean (SEM) is given within the parenthesis

\begin{tabular}{lcl} 
Fungal isolate & Mean Solublized P $(\mathbf{m g}$ P/l) & Media pH \\
\hline Control & $08.25( \pm 0.14)$ & $6.18( \pm 0.017)$ \\
KBF1 & $435.49( \pm 25.33)$ & $4.29( \pm 0.076)$ \\
KBF2 & $307.22( \pm 04.11)$ & $5.08( \pm 0.040)$ \\
KBF3 & $723.58( \pm 15.34)$ & $3.90( \pm 0.017)$ \\
KBF4 & $881.17( \pm 35.43)$ & $4.24( \pm 0.017)$ \\
KBF5 & $222.12( \pm 03.14)$ & $5.28( \pm 0.148)$ \\
KRF1 & $434.85( \pm 06.66)$ & $4.84( \pm 0.525)$ \\
RBF1 & $792.02( \pm 34.13)$ & $3.78( \pm 0.087)$ \\
RBF2 & $492.94( \pm 21.51)$ & $4.63( \pm 0.061)$ \\
RBF3 & $467.84( \pm 27.27)$ & $4.41( \pm 0.029)$ \\
UBF1 & $318.66( \pm 20.95)$ & $4.40( \pm 0.087)$ \\
WBF1 & $585.19( \pm 09.17)$ & $4.01( \pm 0.025)$
\end{tabular}

\section{PHOSPHATE SOLUBILIZATION IN MODIFIED PVK LIQUID MEDIUM} CONTAINING HERP

The mean solubilized $\mathrm{P}$ concentrations and the mean $\mathrm{pH}$ values at 24 and $48 \mathrm{~h}$ of incubation in HERP containing PVK liquid medium were summerized in Table 2. A high significant variation of solubilized $\mathrm{P}$ concentrations was evident among the fungal isolates in 24 hour incubation time at $0.05 \%$ level. Highest solubilization of $44.299( \pm 0.856) \mathrm{mg} \mathrm{P} / \mathrm{l}$ was reported with RBF1 while the lowest $\mathrm{P}$ concentration of $2.899( \pm 0.112) \mathrm{mg} \mathrm{P} / \mathrm{l}$ was seen with isolate $\mathrm{RBF} 2$. The time also played a significant role in solubilization recording a markedly high

Proceedings of the 15 $5^{\text {th }}$ International Forestry and Environment Symposium, 26-27 November 2010. 
solubilized P concentration of $103.408( \pm 6.228) \mathrm{mg} \mathrm{P} / \mathrm{l}$ in KBF2 and the lowest of 10.815 $( \pm 1.155) \mathrm{mg} \mathrm{P} / \mathrm{l}$ by $\mathrm{RBF} 2$, at $48 \mathrm{~h}$ incubation period. This discrepancy in the highest solubilizers at different times may be attributed to fungal growth rates or rates of organic acid production as evidenced by a rapid decrease in $\mathrm{pH}(2.96( \pm 0.03))$ with isolate KBF2, but further investigations into this is necessary to draw a firm conclusion. The mean solubilized $\mathrm{P}$ concentration of the control also showed a slight increase most probably due to the hydrolysis of minerals with time.

When the P solubilization abilities were compared between two media, isolate KBF4 was the best candidate in the modified PVK liquid medium containing $\mathrm{Ca}_{3}\left(\mathrm{PO}_{4}\right)_{2}$ whereas the performance of KBF2 was the best in modified PVK medium containing HERP. This remarkable difference of $\mathrm{P}$ solubilization in two different media reflects that the fungi favoured solubilization of $\mathrm{Ca}_{3}\left(\mathrm{PO}_{4}\right)_{2}$ than rock phosphate. This may be due to the unfavourable growth conditions presented to the isolates by the impurities present in HERP. Additionally, although there were significant declines in $\mathrm{pH}$ of all the treatments in both media, the absence of a strong relationship between $\mathrm{P}$ solubilization and the decrease of $\mathrm{pH}$ in the modified PVK with HERP shown in figure 2, supports the ideas that either the microorganisms are having several other mechanisms to solubilize insoluble phosphates, other than organic acid secretion or the presence of interferences by metal complexes in apatite to the process or growth of the organisms by impurities.

Table 2: Mean solubilized $\mathrm{P}$ concentrations ( $\mathrm{mg} \mathrm{P} / \mathrm{l})$ and mean $\mathrm{pH}$ values at 24 hours and 48 hours of incubation in HERP contained PVK medium: The standard error of the mean (SEM) is given within the parenthesis

\begin{tabular}{lcccc}
\hline & \multicolumn{4}{c}{ Time } \\
\cline { 2 - 5 } Isolate & $\begin{array}{c}\text { Solubilized P } \\
(\mathbf{m g} \text { P/I })\end{array}$ & Mean pH & $\begin{array}{c}\text { Solubilized P } \\
(\mathbf{m g} \text { P/l) }\end{array}$ & Mean pH \\
\cline { 2 - 5 } Control & $2.175( \pm 0.02)$ & $6.23( \pm 0.02)$ & $5.09( \pm 0.42)$ & $5.46( \pm 0.06)$ \\
KBF1 & $24.40( \pm 1.62)$ & $2.78( \pm 0.05)$ & $68.91( \pm 3.86)$ & $2.72( \pm 0.04)$ \\
KBF2 & $24.17( \pm 0.89)$ & $3.26( \pm 0.03)$ & $103.41( \pm 6.23)$ & $2.96( \pm 0.03)$ \\
KBF3 & $24.69( \pm 1.21)$ & $3.47( \pm 0.03)$ & $61.82( \pm 0.29)$ & $2.83( \pm 0.05)$ \\
KBF4 & $11.06( \pm 0.23)$ & $3.40( \pm 0.16)$ & $39.23( \pm 11.29)$ & $2.94( \pm 0.06)$ \\
KBF5 & $26.72( \pm 0.67)$ & $3.07( \pm 0.07)$ & $90.91( \pm 8.09)$ & $2.83( \pm 0.12)$ \\
KRF1 & $3.88( \pm 0.43)$ & $5.88( \pm 0.34)$ & $31.35( \pm 0.68)$ & $4.05( \pm 0.57)$ \\
RBF1 & $44.30( \pm 0.86)$ & $3.37( \pm 0.12)$ & $63.99( \pm 3.06)$ & $3.18( \pm 0.03)$ \\
RBF2 & $2.90( \pm 0.11)$ & $3.58( \pm 0.10)$ & $10.82( \pm 1.16)$ & $2.88( \pm 0.00)$ \\
RBF3 & $18.76( \pm 0.77)$ & $3.88( \pm 0.13)$ & $56.29( \pm 0.87)$ & $2.94( \pm 0.04)$ \\
UBF1 & $22.98( \pm 1.64)$ & $3.39( \pm 0.02)$ & $39.12( \pm 2.66)$ & $2.87( \pm 0.01)$ \\
WBF1 & $27.48( \pm 1.35)$ & $2.71( \pm 0.03)$ & $74.96( \pm 11.24)$ & $2.90( \pm 0.03)$ \\
\hline
\end{tabular}

$\mathrm{n}=3$

Proceedings of the 15 ${ }^{\text {th }}$ International Forestry and Environment Symposium, 26-27 November 2010.

Published by Department of Forestry and Environmental Science, University of Sri Jayewardenepura, Sri Lanka. 


\section{CONCLUSION}

Out of the 12 isolates tested, only 11 showed the ability to solubilize phosphates in the presence of partially solubilized P and HERP. Two fungal isolates, namely KBF4 and KBF2 exhibited high efficiencies in $\mathrm{P}$ solubilization in PVK medium and HERP medium, respectively. The efficiency of phosphate solubilization is significantly high in Pikovskaya medium containing $\mathrm{Ca}_{3}\left(\mathrm{PO}_{4}\right)_{2}$ than that in the medium containing HERP, suggesting interferences to the solubilizing mechanism. Incubation time has a significant effect on HERP solubilization and the production of organic acids. A strong correlation between $\mathrm{P}$ solubilization and media $\mathrm{pH}$ decrease was observed in the PVK medium whereas this was not seen in HERP containing medium. The contradictory results may be due to either the use of other mechanisms to solubilise insoluble phosphates other than the acidulation of the medium or the interferences presented by the metal complexes present as impurities.

\section{REFERENCES}

Chen, Y.P., Rekha, P.D., Arun, A.B., Shen, F.T., Lai, W. Young, C.C., 2005. Phosphate solubilizing bacretia from subtropical soil and their tricalcium phosphate solubilizing ability. Applied Soil Ecology. $34,33-41$.

Didiek, H., Siswanto, Sugiarto, Y., 2001. Bioactivation of poorly soluble phosphate rocks with a phosphorus solubilizing fungus. Soil Science Society. 64, 927-931.

Hameeda, B., Harini, G., Rupela, O.P., Wani, S.P., Reddy, G., 2006. Growth promotion of maize by phosphate solubilizing bacteria isolated from composts and macrofauna. Microbiological research. 163(2), 234-242.

Mikanova, O., Novakova, j., 2002. Evaluation of the P solubilizing actuivity of soil microorganisms and its sensitivity to soluble phosphate. Rostlinna vyroba. 48, 397-400.

Rajankar, P.N., Tambekar, D.H., Wate, S.R., 2007. Study of phosphate solubilization efficiencies of fungi and bacteria isolated from saline belt of Purna river basin. Agriculture and Sciences. 3(6), 701703.

Singal, R., Gupta, R., Kuhad, R.C., Saxena, R.K., 1991. Solubilization of inorganic phosphates by a Basidiomycetous fungus Cuathus. Indian J. Microbiol. 31, 397-401.

Son, H., Park, G., Cha, M., Hoe, M., 2006. Solubilization of insoluble phosphate by a novel salt and pH tolerant bacteria isolated from soybean rhizosphere. Bioresource Technology. 97, 204-210.

Sundara, B. Natarajan, V. Hari, K., 2002. Influence of phosphorus solubilizing bacteria on the changes in soil available phosphorus and sugar cane and sugar yields. Field Crops Reasrch. 77, 43-49.

Vassileva, M., Azcon, R., Barea, J.M., Vassilev, N., 1998. Application of an encapsulated filamentous fungus in solubilization of inorganic phosphates. Biotechnology. 63, 67-72

Proceedings of the 15 ${ }^{\text {th }}$ International Forestry and Environment Symposium, 26-27 November 2010

Published by Department of Forestry and Environmental Science, University of Sri Jayewardenepura, Sri Lanka. 